\title{
TECNOLOGIAS DA INFORMAÇÃO E COMUNICAÇÃO NO PROCESSO DE ENSINO E APRENDIZAGEM
}

\author{
INFORMATION AND COMMUNICATION TECHNOLOGIES \\ IN THE TEACHING AND LEARNING PROCESS
}

Cássia Cristina de Oliveira ${ }^{\mathrm{I}}$

\section{RESUMO}

O artigo tem o intuito de discorrer sobre o uso das novas tecnologias da informação e comunicação na prática docente. Para isso, foi realizado um levantamento bibliográfico sobre as tecnologias da informação e comunicação no processo de ensino aprendizagem no qual foi possível obter informações sobre o conhecimento, utilização e contribuição das tecnologias na prática pedagógica. A metodologia adotada nessa pesquisa é a revisão da literatura. A ação educativa, com o envolvimento das TIC's, poderá ser desenvolvida na perspectiva de promover a experimentação, a descoberta e a construção de aprendizagem significativa. A mediação do processo de ensino aprendizagem com o uso dessas ferramentas requer uma avaliação tanto do processo quanto do resultado. A escola não está alheia à sociedade, mas imersa nela e, assim, é influenciada o tempo todo pelas modificações ocorridas em todas as esferas. As tecnologias de informação (TIC's) são relevantes para o processo de ensino-aprendizagem, e seu uso de maneira crítica e criativa possibilita o desenvolvimento do estudante. Porém, para que isso realmente aconteça são necessárias competências e habilidades tecnológicas e pedagógicas do docente para mediar a construção do conhecimento.

Palavras-chave: Aprendizagem. Ensino. Prática Pedagógica. Tecnologias.

\section{ABSTRACT}

The article aims to discuss the use of new information and communication technologies in teaching practice. For this, a bibliographic survey was carried out on information and communication technologies in the learning teaching process in which it was possible to obtain information about the knowledge, use and contribution of the technologies in pedagogical practice. The methodology adopted in this research is the literature review. The educational action, with the involvement of ICTs, could be developed with the perspective of promoting experimentation, discovery and the construction of meaningful learning. The mediation of the teaching-learning process through the use of these tools requires an evaluation of both the process and the outcome. The school is not alien to society, but immersed in it, and thus is influenced all the time by changes in all spheres. Information technologies (ICTs) are relevant to the teachinglearning process, and their use in a critical and creative way enables student development. However, for this to happen, it is necessary to have the pedagogical and pedagogical skills and abilities of the teacher to mediate the construction of knowledge.

Keywords: Technologies. Pedagogical Practice. Teaching. Learning.

「Secretaria de Educação do Distrito Federal - Brasil. E-mail: cassiayan@gmail.com 


\section{INTRODUÇÃO}

A educação ainda significa possibilidades de mudanças das posições socioeconômicas assimétricas que vigoram na atualidade. Para isso, é importante que os conteúdos trabalhados estejam a serviço da aprendizagem da constituição e/ou restauração do educando como ser humano singular e também como cidadão (LUCKESI, 2009).

No atual contexto educacional, entende-se que não é possível pensar na formação dos docentes sem que estejam presentes as ferramentas tecnológicas, como o computador e a internet. Com isso, as estratégias para a aprendizagem constituemse na arte de definir sobre um conjunto de recursos, que auxiliem no alcance dos objetivos educacionais propostos para o aluno, processo que envolve desde a organização do espaço da sala até a seleção do material a ser usado, como por exemplo recursos audiovisuais, visitas técnicas, internet, etc. (MASETTO, 2003).

A entrada dos computadores na escola possibilitou a criação de um novo espaço dentro do ambiente escolar: a Sala de Tecnologia Educacional (STE). Entretanto, é importante ressaltar que o acesso às tecnologias da informação e comunicação não acontece simplesmente com a instalação dos computadores na escola, nesse espaço diferenciado, mas pela necessidade de mediação de professores, por meio do desenvolvimento de habitus e saberes docentes para trabalhar, acessar e interagir com essas tecnologias no cotidiano da escola. Nesse sentido, avançar para além da simples implementação técnica de computadores nas escolas, significa projetar análises sobre como as relações didáticopedagógicas acontecem a partir das novas tecnologias e que dificuldades há nessas relações (QUILES, 2008,p.13).

Nesse sentido, é importante ressaltar que as ferramentas de TI devem ser utilizadas de forma adequada e aliadas aos objetivos do ensino-aprendizagem para que possibilitem o crescimento do estudante. A utilização das TIC's vem mobilizando os educadores no sentido de construir e mediar o conhecimento. Com vistas nesses pressupostos, o presente artigo tem o intuito de discorrer sobre o uso das novas tecnologias da informação e comunicação na prática docente.

\section{MATERIAL E MÉTODO}

Foi realizado um levantamento bibliográfico sobre as tecnologias da informação e comunicação no processo de ensino-aprendizagem, no qual foi possível ter informações sobre o conhecimento, utilização e contribuição das tecnologias na prática pedagógica. Para isso, valeu-se como metodologia de pesquisa no presente artigo a revisão da literatura.

"Embora em quase todos os estudos seja exigido algum tipo de trabalho dessa natureza, há pesquisas desenvolvidas exclusivamente a partir de fontes bibliográficas". (GIL, 2002, p.44). A revisão é um tipo de pesquisa que faz uso de fontes de informações bibliográficas ou eletrônicas para obter resultados de estudos de outros pesquisadores, com a intenção de fundamentar teoricamente um determinado objeto de estudo (ROTHER, 2007). 


\section{RESULTADOS E DISCUSSÃO}

A educação é adquirida ao longo da vida dos indivíduos e envolve a leitura, a interpretação e a assimilação dos fatos, eventos e acontecimentos que ocorrem de maneira isolada ou em contato com grupos e organizações. A cultura é relevante para entender os processos educativos. A cultura é percebida como modos, formas e processos de atuação dos homens dentro de um determinado contexto histórico, onde ela se constrói e está constantemente se modificando, estando continuamente influenciada por valores que se sedimentam em tradições e são transmitidos de uma geração para outra (GOHN, 2001).

A educação informal é própria da educação em seu sentido lato, ou seja, o que se adquire ao longo da vida e a educação não formal pode ser entendida como aquela modalidade vinculada às ONGS, clubes, academias, etc.. A valorização dos processos de aprendizagem em grupos e a importância dos valores culturais que articulam as ações das pessoas é importante para vida do ser humano. Assim, o campo da Educação é ampliado para outras dimensões além da escola, abrange não só conteúdos teóricos e práticos, mas também, valores e atitudes para viver, sobreviver e desenvolver a capacidade humana.

A educação em seu sentido estrito, também chamada de educação escolar ou educação sistemática é aquela que tem, no seu bojo, um compromisso político, ético e com a formação voltada para o exercício da cidadania. Além do mais, a educação é meio de transformação social e cada vez mais a Escola exercerá ou poderá exercer um papel que a ela jamais foi atribuído em tempos passados: o de ser a instituição formadora dos seres humanos (RODRIGUES, 2001, p. 253).

A instituição escolar como impulsionadora do desenvolvimento da pessoa, requer práticas docentes alicerçadas em uma postura crítica. $\mathrm{O}$ educador não deve perder de vista o educando na totalidade, por isso é relevante direcionar sua prática a partir de princípios norteadores de uma ação cidadã, criando o espaço da receptividade viva para o aluno, oferecendo-lhe condições para que se sinta num espaço seguro, sem ameaças, julgamentos ou desqualificações.

[...] Nesse contexto, o educando aprende e, por aprender, se desenvolve [...] O, então, educador é aquele que acolhe, nutre, sustenta e confronta o educando, tendo em vista oferecer-lhe condições para que construa e siga seu caminho na vida com criatividade e independência (LUCKESI, 2009, p. 47).

Libâneo (1997) fez importantes contribuições para a discussão da educação como meio que possibilita transformação social e que propõe uma educação cidadã, ética, social e profissional. Ainda, pontua que as concepções pedagógicas de cunho crítico consideram a educação como meio de emancipação humana que possibilita transformação nas relações sociais.

Para que ocorra crescimento e o exercício da cidadania no Brasil é necessária a efetivação e qualificação da escolarização básica, com o enfrentamento das dificuldades do sistema de ensino como um todo. Isso requer melhorias na condição de trabalho do professor, nas práticas de gestão escolar, na questão pedagógica e 
didática interna à escola (LIBÂNEO, 1997). As mudanças no contexto educacional precisam se adequar às necessidades sociais e, dentro desse contexto, usar as novas ferramentas, entre elas as TIC's como apoio e manutenção do aprendizado.

\section{TIC's nos Processos Educativos}

As TIC's podem ser definidas como um conjunto de recursos tecnológicos, utilizados de forma integrada, com o objetivo de proporcionar mudanças e transformações no cotidiano das pessoas. Conforme Garcia et al (2011) a tecnologia digital interativa é uma produção inventada pelo homem que requer a comunicação interativa, onde as pessoas têm possibilidades para intervir no conteúdo ou programa com o qual interagem, sendo que a ferramenta tecnológica é a mediadora desse processo, que é dialógico.

As TIC's são utilizadas das mais variadas formas, no dia a dia, na indústria, no comércio, no setor de investimentos, na educação e nos processos de ensino-aprendizagem. O desenvolvimento de hardwares e softwares diversificou as diversas formas de utilização e operacionalização da comunicação e dos processos decorrentes em meios virtuais.

O maior impulso desses recursos ocorre no meio social, sendo que sua utilização popular fez com que as pessoas comuns se familiarizassem com as novas tecnologias. $\mathrm{O}$ aprimoramento desses recursos foi criando novos sistemas de comunicação e informação, contribuindo para a criação das redes sociais.

Cada vez mais pessoas buscam interagir utilizando meios como o e-mail, o chat, os fóruns, a agenda de grupos online, comunidades virtuais, web cam, entre outros, revolucionando as relações humanas. A troca de informações gera novos conhecimentos e competências entre os profissionais.

Garcia et al (2011) afirmaram que o avanço e a disseminação das TIC's na sociedade são amplamente significativos e têm a possibilidade de transformar o comportamento das pessoas, podendo gerar um descompasso entre as gerações de quem ensina e de quem aprende. Os pesquisadores ressaltam que esse processo acarreta, inevitavelmente, consequências e questões a serem discutidas na Educação.

A escola é o espaço mais apropriado para a conquista da cultura, da ciência e para o desenvolvimento intelectual. No entanto, as suas condições e o seu funcionamento são modestos para disputar espaço com os meios de comunicação e outras linguagens (LIBÂNEO, 1997).

Com isso, é relevante e necessária a integração das tecnologias aos processos educativos, especificamente das TIC's, uma vez que elas estão cada vez mais presentes no cotidiano dos estudantes e que seu uso na educação, no trabalho e em outros contextos, é uma competência básica a ser possibilitada pelos educadores no conjunto do currículo escolar e de suas disciplinas (RIBEIRO; CASTRO; REGATTIERI, 2007). Então, cabe ao educador investir em estratégias que lhe possibilitem familiarizar-se com as TIC's.

As diferentes formas de integração das 
TIC's são criadas para facilitar o desenvolvimento e a interação, aspecto que favorece o processo educativo e possibilita o avanço da educação no país. Contudo, o uso das TIC's no processo de ensino aprendizagem depende de vários fatores que estão interligados entre si, tais como formação profissional, a competência para interagir usando as novas tecnologias, a infraestrutura do ambiente, os recursos tecnológicos disponíveis ao estudante, os recursos motivacionais e a autonomia.

\section{As TIC's e o processo de ensino- aprendizagem}

A sociedade contemporânea é a sociedade da informação e do conhecimento, na qual a aprendizagem não se constrói somente nos espaços de sala de aula centrado no professor, na função e papel de transmissor do conhecimento. Aliás, o ensino demanda que o professor seja o mediador na construção do conhecimento, construído ao longo da vida da pessoa, aprimorado na escola e que pode ser reelaborado sempre que novas demandas surgirem no cotidiano de cada um.

Por isso, considera-se que a tecnologia não gera a aprendizagem por si só (BOGDANOV, 1999) e pode ser vista como complementar e facilitadora da organização e eficácia do processo de ensino e aprendizagem, permitindo atender às necessidades individuais.

Partindo desse pressuposto Ribeiro,

Castro e Regattieri (2007) pontuam que as tecnologias por si mesmas não são capazes de gerar transformações na relação pedagógica, podendo atuar tanto para sustentar um modelo educativo conservador quanto para possibilitar uma aprendizagem contextualizada, interdisciplinar, interativa, colaborativa e prazerosa.

Peixoto e Araújo (2012), com base em um estado da arte realizado sobre o uso do computador na educação escolar, no período de 1997 a 2007 no Brasil, apresentam os fundamentos do discurso predominante sobre as relações entre as tecnologias e a educação e sugerem duas visões sobre os usos do computador na educação: uma visão instrumental, que demonstra a incorporação das TIC's enquanto recursos didático-pedagógicos moldados pelas pessoas, e outra visão da tecnologia como um instrumento que define a configuração social e cultural.

Além do mais, Alonso (2008) questiona o papel central que muitas vezes é atribuído às TIC's, na posição de instrumentos modificadores das práticas dos docentes. Ainda salienta que o uso das TIC's no contexto escolar e as significações sobre elas têm implicado transformações que relativizam a função do professor como transmissor de conhecimento, deslocando o centro da questão para o "protagonismo" dos estudantes. O problema é que a escola, como instituição, está ainda marcada pela lógica da transmissão, fazendo colidir com a lógica das TIC's e a lógica escolar. Utilizar as tecnologias digitais nos processos educativos requer postura ativa e crítica do educador. Uma vez que o domínio das TIC's poderá criar oportunidades na prática docente para reflexão, construção e integração de conceitos; para isso é preciso 
[...] superar a crença de que a tecnologiaé neutra e serve como simples instrumento facilitador do trabalho pedagógico assim como de que ela possui capacidade e autonomia para estabelecer, por si mesma as mudanças e as transformações de paradigmas (GARCIA et al. 2011, p.86).

As TIC's podem ser utilizadas no trabalho docente de maneira crítica e criativa, mas, para isso, algumas competências são necessárias

(Quadro 1). Garcia et al. (2011) organizaramas competências em quatro grandes eixos: tecnológico, pedagógico, sujeito e exploratório, considerando sua relação de proximidade e identificação.

Essas competências são necessárias para o docente que usa as TIC's assumir o papel de mediador no processo de ensino aprendizagem. Além disso, Ribeiro et al. (2007) sugerem que é possível potencializar o trabalho escolar, por meio do uso e da criação de recursos tecnológicos, sendo que os envolvidos nos processos educativos podem ser consumidores e também produtores de tecnologias.

As TIC's são necessárias em diversos setores da sociedade, a exemplo da escola. A tecnologia de certa forma já faz parte da educação há séculos, desde o livro impresso, do uso do lápis e do quadro-negro, da televisão e vídeo em sala, e seu desenvolvimento atinge as formas de vida na sociedade, sendo que a escola tem uma "função mediadora entre a cultura hegemônica da comunidade social e as exigências educativas de promoção do pensamento reflexivo" (LITWIN, 2001, p. 131).

Quadro 1- Competências para uso das TIC's no trabalho docente
TECNOLÓGICA

- Domínio de ferramentas e aplicativos para integrar as tecnologias no processo de ensino-aprendizagem.

Saber fazer escolhas conscientes das tecnologias.

- Domínio de ferramentas de criação e aplicação com o uso da internet.

\begin{tabular}{|c|c|}
\hline da internet. & $\begin{array}{l}\text { - Compreensão intelectual do } \\
\text { meio digital. }\end{array}$ \\
\hline \multicolumn{2}{|c|}{ COMPETÊNCIAS } \\
\hline $\begin{array}{l}\text { SUJEITO } \\
\text { - Compreensão das } \\
\text { ferramentas intelectuais. } \\
\text { - Competência } \\
\text { comunicacional: linguísticas, } \\
\text { contextuais, interativas. } \\
\text { - Levar em consideração o } \\
\text { afeto nas relações entre } \\
\text { professor, aluno e meio } \\
\text { digital. }\end{array}$ & $\begin{array}{l}\text { EXPLORÁTORIA } \\
\text { - Saber como aprender, } \\
\text { conhecer os estilos de } \\
\text { aprendizagem. } \\
\text { - Formação para o uso livre e } \\
\text { criativos das mensagens. } \\
\text { - Conhecer as tecnologias de } \\
\text { comunicação em masssa e } \\
\text { explorá-las como ferramentas } \\
\text { capazes de potencializar a } \\
\text { relação de ensino- } \\
\text { aprendizagem. }\end{array}$ \\
\hline
\end{tabular}

Fonte: Garcia et al (2011, p.86).

Em outras palavras, poderíamos afirmar que contexto escolar está sendo constantemente modificado, o uso do "quadro e do giz" como os principais recursos didáticos estão sendo substituídos por computadores, TV, vídeo, rádio e outras tecnologias (MORAN, 2005). Assim, a incorporação das tecnologias, mesmo de forma lenta e restrita, vem acontecendo.

[...] as apropriações das tecnologias pelas escolas passam por três etapas, sendo que na primeira, as tecnologias são utilizadas para melhorar o que já se vinha fazendo (melhorar o desempenho e a gestão, automatizar processos, diminuir custos). $\mathrm{Na}$ segunda etapa, a escola insere parcialmente as tecnologias no projeto educacional. [...] desenvolve alguns projetos, há atividades no laboratório de informática, mas mantém intocada estrutura de aulas, disciplinas e horários. $\mathrm{Na}$ terceira, que começa atualmente, como o amadurecimento de sua implantação e o avanço da integração das tecnologias, as universidades e escolas repensam seu projeto pedagógico, seu plano 
estratégico, e introduzem mudanças significativas [...] (MORAN, 2007, p.1)

Conforme Demo (1991) apud Sampaio e Leite (2001) na atualidade, com o avanço tecnológico, a escola tem a função de preparar os cidadãos para o trabalho e para a vida. Se ficar à margem do processo de "tecnologização" da sociedade, corre o risco de se tornar defasada, desinteressada, alienada, e de não cumprir suas funções.

Pela incorporação das novas tecnologias no cotidiano da escola é possível uma diversificação de conhecimentos, além de uma renovação das formas de se atingir o conhecimento, tendo a tecnologia como objeto e como meio de se chegar ao conhecimento. Através da utilização de uma diversidade de recursos tecnológicos no ambiente escolar, é possível que o aluno se familiarize com a gama de tecnologias existentes na sociedade, possibilitando que estas sejam desmistificadas e democratizadas (QUILES, 2008, p.12).

Existe a necessidade de formação continuada do professor para que ele possa fazer uso adequado das TIC's, facilitar e mediar a construção do conhecimento do estudante e auxiliar na superação das desigualdades sociais. A utilização das TIC's na sala de aula só será útil quando o professor dispuser de ferramentas para interpretar, refletir e dominá-las criticamente.

As TIC's na escola, conforme Moran (2009) requerem um docente como mediador e organizador de processos e não como reprodutor de informações; que seja um profissional capaz de transformar o espaço escolar, modificar e inovar o processo de ensino-aprendizagem. A escola não atenderá às demandas de seus alunos somente com a disponibilidade das TIC's; aliás, é necessária a formação continuada dos professores para que a mediação do conhecimento, com seu uso, ocorra de maneira crítica.

\section{CONSIDERAÇÕES FINAIS}

As TIC's constituem um conjunto de recursos tecnológicos que podem possibilitar modificações na vida das pessoas. Na educação, podem contribuir com o processo de ensino aprendizagem à medida que são utilizadas como mais um recurso pedagógico auxiliar da mediação do conhecimento.

A ação educativa, com o envolvimento das TIC's, poderá ser desenvolvida na perspectiva de promover a experimentação, a descoberta e a construção de aprendizagem significativa. A mediação do processo de ensino-aprendizagem com o uso dessas ferramentas requer uma avaliação tanto do processo quanto do resultado. A escola não está alheia à sociedade; ao contrário, está imersa nela sendo influenciada todo tempo pelas modificações ocorridas em todas as esferas sociais. Considerando a importância que as TIC's têm na atualidade é relevante discutir sobre seu uso, buscando superar as fragilidades de sua inserção na ação pedagógica.

\section{REFERÊNCIAS BIBLIOGRÁFICAS}

ALONSO, K M. Tecnologias da informação e comunicação e formação de professores: sobre rede e escolas. Educação e Sociedade, Campinas, vol. 29, n. 104, Especial, p. 747-768, out. 2008.

BOGDANOV, D. Information \& communication technologies impact on academic curricula.Educational Technology 
\&Society, v. 1, n. 2, 1999.

GARCIA, M. F. et al. Novas competências docentes frente às tecnologias digitais interativas. Rev. Teoria e Prática da Educação, v. 14, n. 1, p. 79-87, jan./abr. 2011.

GIL, Antônio Carlos. Como elaborar projetos de pesquisa. 4. ed. - São Paulo: Atlas, 2002.

GOHN, M. G. M. Educação Não-Formal e Cultura Política. São Paulo: Cortez, 2001.

LIBÂNEO, J C. Pedagogia e modernidade: presente e futuro da escola. In:

GHIRALDELLI, J. P.. Infância, escola e modernidade. São Paulo: Cortez, 1997, pp. 127-176.

LITWIN, E. (Org.). Tecnologia Educacional: políticas, histórias e propostas. 2. ed. Porto Alegre: Artes Médicas, 2001.

LUCKESI, C. C. O Educador: qual o seu papel na contemporaneidade? In: D"ÁVILA, C..Ser professor na contemporaneidade: desafio, ludicidade e protagonismo. Curitiba: Editora CRV, 2009, pp. 41-52.

MASETTO, M. T. Competências do

Professor Universitário. São Paulo: Summus Editora, 2003.

MORAN, José Manuel. Novas Tecnologias e Mediação Pedagógica. Papirus Editora, 2009.

As possibilidades das redes de aprendizagem. Texto adaptado do capítulo 4 do livro A educação que desejamos: novos desafios e como chegar lá, da Editora Papirus, p.89-111, 2007. Disponível em: http://www.eca.usp.br/prof/moran/site/textos/t ecnologias_eduacacao/redes_aprendizagem.pd f Acesso em: 2 jan. 2017.

PEIXOTO, J. P.; ARAÚJO, C. H. S.

Tecnologia e educação: algumas considerações sobre o discurso pedagógico contemporâneo. Educ. Soc., Campinas, v. 33, n. 118, p. 253268, jan./mar. 2012.

RIBEIRO, A; CASTRO, J. M.; REGATTIERI, M. M. G. Tecnologias na sala de aula: uma experiência em escolas públicas de ensino Médio. Brasília: UNESCO, MEC, 2007.

RODRIGUES, N. Educação: da formação humana à construção do sujeito ético.

Educação \& sociedade, Campinas, ano XXII, n. 76 , out./2001.

QUILES, Cláudia Natália Saes a relação escola, tecnologia, ensinar e aprender: a teoria crítica como suporte de análise. Revista Educação, Artes e Inclusão, v. 1, n. 1, 2008. Disponível em:

http://200.19.105.203/index.php/arteinclusao/art icle/view/1629 Acesso em: jan. 2017.

ROTHER, Edna Terezinha. Revisão sistemática $X$ revisão narrativa. Acta Paul Enferm, n. 20, v.2, 2007. Disponível em: http://www.scielo.br/pdf/ape/v20n2/a01v20n2.p df Acesso em jan. 2017.

SAMPAIO, M. N.; LEITE, L. S.

Alfabetização tecnológica do professor. 2. ed. Petrópolis: Vozes, 2001.

\section{Endereço para correspondência:}

Cássia Cristina de Oliveira.

Secretaria de Estado de Educação do Distrito Federal, Secretaria de Estado de Educação do Distrito Federal.

Quadra SBN Quadra 2, Asa Norte, 70040020 -

Brasília, DF - Brasil - Caixa-postal: 73350106.

E-mail: cassiayan@gmail.com

\section{Como citar este artigo (Formato ABNT):}

OLIVEIRA, Cássia Cristina de. As tecnologias da informação e comunicação no processo de ensino e aprendizagem. Educação, Psicologia e Interfaces, vol.1, n.1, p. 23-30, 2017. DOI: https://doi.org/10.37444/issn-2594-5343.v1i1.5

Recebido: 04/03/2017.

Aceito: 05/04/2017. 